\title{
Bronchiolitis obliterans organising pneumonia in a patient with ulcerative colitis
}

\author{
C R SWINBURN, G J JACKSON, I COBDEN, T ASHCROFT, G N MORRITT, \\ P A COR RIS
}

\author{
From the Regional Cardiothoracic Unit and the Department of Histopathology, Freeman Hospital, Newcastle \\ upon Tyne
}

ABSTRACT A young woman with ulcerative colitis developed pneumonia, which responded to corticosteroids. Histological examination showed this to be bronchiolitis obliterans organising pneumonia.

Various pulmonary disorders have been reported as extraintestinal manifestations of ulcerative colitis. These include chronic bronchial suppuration and bronchiectasis ${ }^{1-3}$ (which may be steroid responsive $\left.{ }^{3}\right)$, pulmonary vasculitis, ${ }^{4}$ and severe steroid responsive pneumonia complicated by pyoderma gangrenosum. ${ }^{5}$ We report a case of severe steroid sensitive pneumonia occurring in a young woman with quiescent ulcerative colitis. Histological examination showed bronchiolitis obliterans organising pneumonia. ${ }^{6}$

\section{Case report}

A 20 year old woman presented in 1983 with weight loss, loose motions, and passage of blood and mucus rectally. Ulcerative colitis was diagnosed on the basis of a barium enema, sigmoidoscopy, and biopsy. Her haemoglobin concentration was $11.0 \mathrm{~g} / \mathrm{dl}$ and white cell count $15.5 \times 10^{9} / 1$ with an eosinophil count of $2.5 \times 10^{9} / 1$. The erythrocyte sedimentation rate (ESR) was $50 \mathrm{~mm}$ in one hour. She was receiving no treatment and her chest radiograph was normal. She was initially treated with sulphasalazine, colifoam enemas, and occasional courses of systemic corticosteroids. In March 1986 mesalazine was substituted for suphasalazine at a dose of $400 \mathrm{mg}$ twice daily initially; subsequently she was maintained on $800 \mathrm{mg}$ thrice daily.

In March 1987 she presented with fever, anorexia, a dry cough, breathlessness on exertion, and central pleuritic chest pain. On examination she was febrile $\left(38^{\circ} \mathrm{C}\right)$ and there was no finger clubbing. Her heart rate was 120 beats/min and bronchial breathing was heard posteriorly in the right chest. A chest radiograph showed peripheral shadowing in the right middle and lower zones. Investigations showed her haemoglobin concentration to be $13.3 \mathrm{~g} / \mathrm{dl}$, white cell count $14.9 \times 10^{9} / 1$, eosinophil count $2.2 \times 10^{9} / 1$ and ESR $93 \mathrm{~mm}$ in one hour. Erythromycin $500 \mathrm{mg}$ four times daily for two weeks resulted in no symptomatic improvement and a chest radiograph showed increased shadowing (fig 1).

On admission the findings from clinical examination and the blood count were essentially unchanged. Routine biochemical and liver function tests gave normal results except

Address for correspondence: Dr C R Swinburn, Regional Cardiothoracic Unit, Freeman Hospital, Newcastle upon Tyne NE7 7DN. (Reprints will not be available.) for increased alkaline phosphatase activity (125 (normal 532) IU/l). Bronchial washings were smear and culture negative for acid fast bacilli and no organisms were seen after Gram staining or subsequent culture. Pleural aspiration produced a small amount of straw coloured fluid with a protein content of $43 \mathrm{~g} / \mathrm{l}$ and no organisms (including acid fast bacilli) were seen after staining or culture. Pleural biopsy was complicated by a hydropneumothorax necessitating underwater seal drainage. The provisional histological report on the biopsy specimen suggested a poorly differentiated adenocarcinoma, so she was transferred to the regional cardiothoracic unit for thoracotomy. At this time the results of her routine blood tests were essentially unchanged except that in addition to the increased alkaline phosphatase activity $\gamma$ glutamyl transpeptidase activity was now increased at 138 (normal < 40) IU/l and aspartate transaminase at $257(<37)$ IU/l. Further investigations included negative results in an autoantibody screen (other than rheumatoid factor $1: 80$ ), normal serum electrophoresis, and normal gammaglobulins,

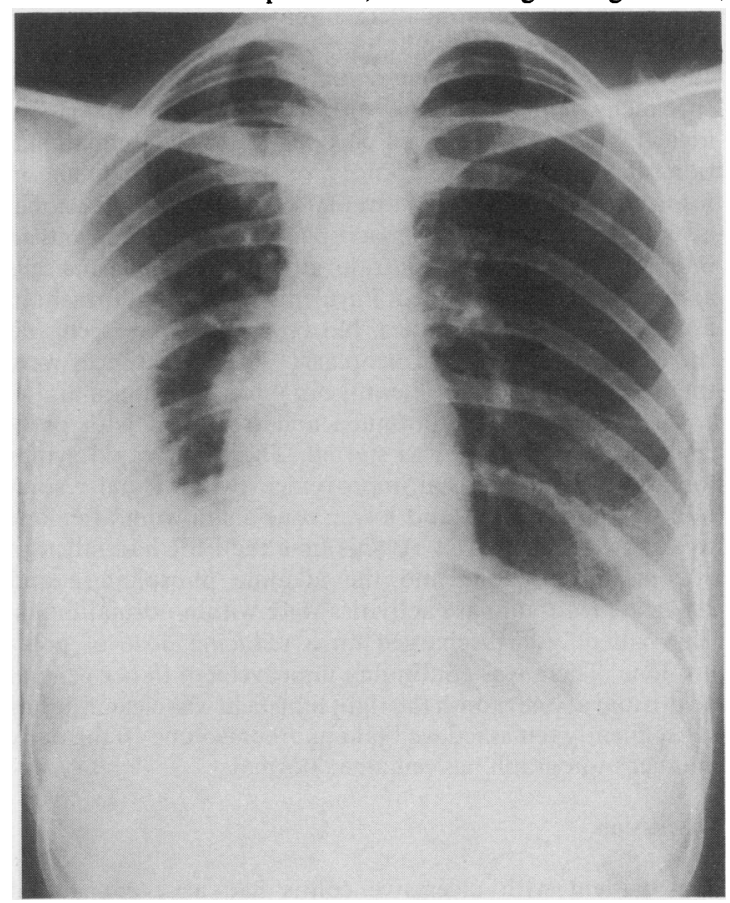

Fig 1 Chest radiograph on admission to hospital showing extensive peripheral shadowing in the right middle and lower zones. 


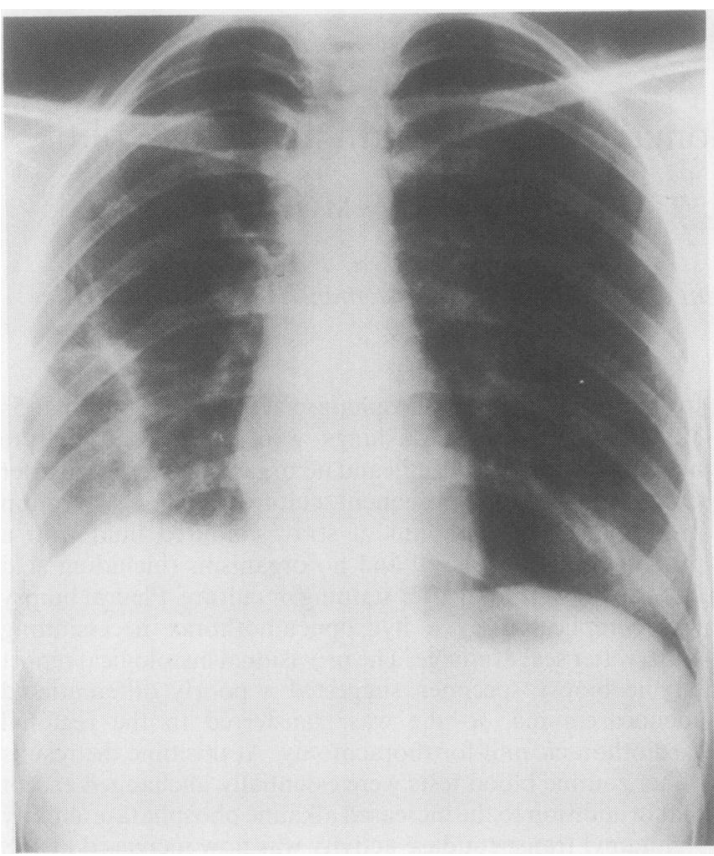

Fig 2 Chest radiograph after treatment with prednisolone $40 \mathrm{mg}$ daily for 7 days.

including IgE. Stool examination showed no parasites and skin testing for common allergens gave negative results.

At thoracotomy the right lung was collapsed with areas of consolidation; the pleura appeared normal. Biopsy specimens of the right lung and pleura were taken. Histologically the pleura showed chronic non-specific inflammation. The lung showed knots of granulation tissue in respiratory bronchioles, alveolar ducts, and occasional alveoli. There were foamy macrophages in the alveoli and an interstitial lymphocytic infiltrate, although a few plasma cells and eosinophils were noted. Purulent exudate was present in non-respiratory bronchioles. No organisms were seen and there was no evidence of neoplasia. The appearances were those of bronchiolitis obliterans organising pneumonia.

Mesalazine was discontinued and treatment with prednisolone $40 \mathrm{mg}$ a day was started. There was rapid symptomatic and radiological improvement with virtual resolution of the right mid and lower zone shadowing after one week's treatment (fig 2). At this time the ESR had fallen to $30 \mathrm{~mm}$ in one hour and the alkaline phosphatase and aspartate transaminase activities were within normal limits. The patient was discharged on a reducing dose of prednisolone. There was continuing improvement in her general health and at one month the right lung field was clear. She has subsequently remained well taking prednisolone $10 \mathrm{mg}$ daily and her radiograph has remained normal.

\section{Discussion}

This patient with ulcerative colitis had a severe steroid responsive pneumonitis with the histological features of bronchiolitis obliterans organising pneumonia. Eight patients with a similar disorder were reported in 1983 and the condition was called cryptogenic organising pneumonitis because of the absence of an infective or other actiologic agent.? In seven patients there was no associated illness, b $\vec{f}$ in one there was evidence of autoimmune disease. Sut sequently a retrospective series of 57 patients with a similia clinical syndrome and similar radiological and histologic findings was reported, and the condition named bronchiolites obliterans organising pneumonia." In this larger series the illness was idiopathic in 50 patients, associated with in connective tissue disorder in five, and caused by aspiration $\mathbb{R}$ two.

A case of severe steroid responsive pneumonitis in associs tion with ulcerative colitis has been previously reported. ${ }^{5}$ The similarity of the clinical and radiological features in this caşe and our own led us to review the histological sections of thef earlier case. This was in many respects similar, showing intra-alveolar exudate of fibrin and clumps of foamy macro phages in various stages of organisation. The specimen was however, smaller and included no bronchioles, and so it w\& not possible to be certain that this case was histologically identical.

Although our patient had peripheral blood eosinophil this was present when she was first seen and antedated amo drug treatment for her ulcerative colitis. She was not atop: her serum IgE concentration was within the normal range, and the histological features were not those of eosinophilic pneumonia. Treatment with sulphasalazine has be\& associated with pulmonary infiltrates, ${ }^{8}$ but in this cage sulphasalazine had been discontinued a year before to development of the pneumonia. There are no reports of a such adverse reactions to mesalazine, which the patient hâd tolerated well for a year. None of the previously reportad cases of bronchiolitis obliterans organising pneumonio were believed to be drug related, and we think that this case was very unlikely to be due to a drug reaction.

Bronchiolitis obliterans organising pneumonia may be rare association of ulcerative colitis. The importance of this diagnosis lies in its prompt response to corticosteroids.

We are grateful to Professor B Corrin, Brompton Hospit若 London, for reviewing the lung biopsy specimen.

\section{References}

1 Higgenbottom T, Cochrane GM, Clark TJH, Turner D, Millis $B$ Seymour W. Bronchial disease in ulcerative colitis. Thor 1980;35:581-5.

2 Kraft SC, Earle RH, Roester M, Esterly JR. Unexplainêd bronchopulmonary disease with inflammatory bowel disease. Arch Intern Med 1976;136:454-9.

3 Butland RJA, Cole P, Citron K, Turner-Warwick M. Chroni bronchial suppuration and inflammatory bowel disease. $Q O$ Med 1981;197:63-75.

4 Isenberg JI, Goldstein H, Korn AS, Ozeran RS, Rosen Pulmonary vasculitis - an uncommon complication Qs ulcerative colitis. $N$ Engl J Med 1968;279:1376-7.

5 McCulloch AJ, McEvoy A, Jackson JD, Jarvis EH. Severe sterơd responsive pneumonitis associated with pyoderma gangre⿻ osum and ulcerative colitis. Thorax 1985;40:314-5.

6 Epter GR, Colby TV, McLoud TC, Carrington CB, Gaenster E Bronchiolitis obliterans organising pneumonia. $N$ Engl $J M t$ 1985;312:152-8.

7 Davison AG, Heard BE, McAllister WAC, Turner-Warwi家 MEH. Cryptogenic organising pneumonitis. $Q J$ M 1983;207:382-94.

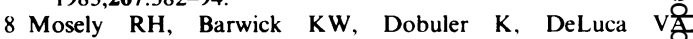
Sulphasalazine-induced pulmonary disease. Dig Dis 1985;30:901-4. 